\title{
Sensorless Control for the EVT-Based New Dual Power Flow Wind Energy Conversion System
}

\author{
Ying Zhu ${ }^{1, *}$ (D), Ming Cheng ${ }^{2}$ (D) and Haixiang Zang ${ }^{1}$ \\ 1 College of Energy and Electrical Engineering, Hohai University, Nanjing 211100, China; \\ zanghaixiang@hhu.edu.cn \\ 2 School of Electrical Engineering, Southeast University, Nanjing 210096, China; mcheng@seu.edu.cn \\ * Correspondence: yingzhu@hhu.edu.cn
}

Received: 15 May 2017; Accepted: 20 June 2017; Published: 30 June 2017

\begin{abstract}
The dual power flow wind energy conversion system (DPF-WECS) is a novel system which is based on the electrical variable transmission (EVT) machine. The proposed sensorless control for the DPF-WECS is based on the model reference adaptive system (MRAS) observer by combining the sliding mode (SM) theory. The SM-MRAS observer is on account of the calculations without the requirement of the proportional-integral (PI) loop which exists in the classical MRAS observer. Firstly, the sensorless algorithm is applied in the maximum power point tracking (MPPT) control considering the torque loss for the outer rotor of the EVT. Secondly, the sensorless control is adopted for the inner rotor control of the EVT machine. The proposed sensorless control method based on the SM-MRAS for the DPF-WECS is verified by the simulation and experimental results.
\end{abstract}

Keywords: dual power flow (DPF); electrical variable transmission (EVT); wind energy conversion system (WECS); sensorless; sliding mode (SM); model reference adaptive system (MRAS); maximum power point tracking (MPPT)

\section{Introduction}

Wind energy is nearly the most mature and promising renewable energy source at present. Many kinds of wind energy conversion systems (WECSs) are researched, which can be roughly divided into constant speed WECSs and variable speed WECSs [1-3]. Nowadays, the variable speed WECSs are the mainstream due to the high utilization ratio of the wind energy, and there are two popular variable speed WECSs, namely the doubly-fed induction generator (DFIG)-based WECS with a multi-level gearbox, and the direct-drive WECS based on the permanent magnet synchronous generator (PMSG). However, both the two WECSs are connected to the grid through converters which will bring serious harmonic pollution to the grid.

Hence, a dual power flow system (DPF-WECS), as shown in Figure 1, has been proposed in recent years $[4,5]$. The DPF-WECS is composed of a wind turbine (WT), an electrical variable transmission (EVT) machine, a back-to-back inverter and a synchronous generator (SG). The energy storage system (ESS) can be configured and applied to adjust the power flow as shown in Figure 1. It needs to be mentioned that the DPF-WECS can operate successfully without the ESS, while the output power can not be adjusted flexibly at this time, just like other WECSs. The EVT consists of an electrical port (stator \#1) and two mechanical ports (permanent magnet outer rotor \#2 and wound inner rotor \#3). The EVT is similar to a variable gearbox which is in charge of connecting the WT and the SG [5]. The outer rotor of the EVT can accept any input speed in the rated speed range and the inner rotor can output a constant speed. Thus, a traditional SG can be used to produce electrical power with the fixed voltage and fixed frequency to the grid by connecting with the inner rotor. Hence, since no converters are connected to the grid directly, DPF-WECS offers the grid clean power without the harmonic pollution. 
Additionally, the DPF-WECS based on the EVT operates with higher reliability and lower maintenance cost than WECSs based on traditional multi-level mechanical gearboxes.

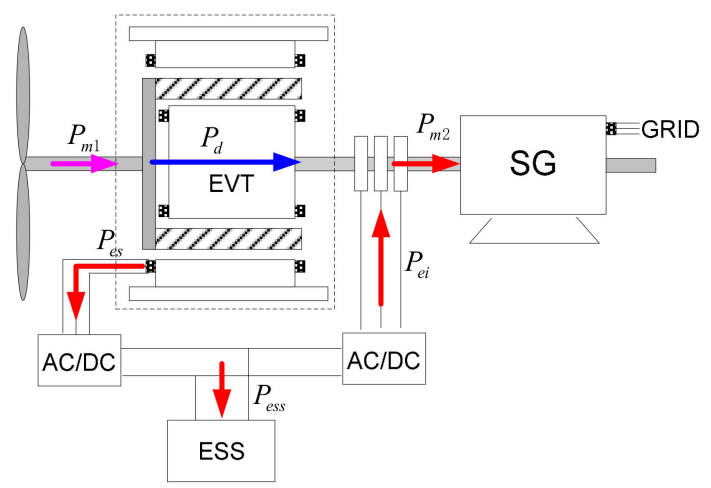

Figure 1. Configuration of the DPF-WECS based on the EVT.

The inner rotor speed of the EVT machine must remain unchanged so that the SG can generate electricity that meets the grid requirements. Thus, the inner rotor speed and position should be measured accurately to attain precise control. However, the inner rotor position, especially the initial position, is quite difficult to measure by traditional sensors due to both of the rotors of the EVT machine are being rotational. Thus, sensorless control seems a good choice for the EVT machine, especially for its inner rotor. The traditional model reference adaptive systems (MRAS)-based sensorless strategy is already applied to the inner rotor control for the EVT machine [5], but the sensorless control for the outer rotor is not referred to in the existing literatures.

At present, many strategies have been proposed for the rotor speed and position estimation in the PMSG drives, such as methods based on the back electromagnetic force (EMF), extended Kalman filter (EKF) methods, reduced observer methods, adaptive approaches, signal injection methods when in a low speed range, and so on [6-9]. Among these techniques, the observer based on the MRAS is a very common choice to realize the sensorless control because of its simplicity and few calculations [10]. The traditional MRAS observers generate the estimated speed through a fixed-gain PI controller since PI controllers have a simple structure and can achieve good performance in a wide range of operation. However, the gain parameters of the PI are difficult to choose. Additionally, the fixed-gain PI regulator is hardly able to provide the continuous good performance due to the varying operating conditions [11,12]. Therefore, the MRAS observer combining of the sliding mode (SM) technique is proposed to replace the traditional PI regulator to estimate the speed and position of the EVT machine for the DPF-WECS in this paper. Then, the performance of the proposed sensorless control for the DPF-WECS is validated by the simulation and experimental results, which is both applied in the outer rotor and inner rotor of the EVT.

Maximum power point tracking (MPPT) control is indispensable for the WECSs. Many types of MPPT methods are proposed in previous papers, such as the optimum tip speed ratio (TSR) method, the power feedback (PF) method, the hill climb searching (HCS) method, and so on [13-19]. The PF is the most popular MPPT strategy and is relying on the generator speed and the wind turbine characteristics, where the wind speed is not needed. However, for obtaining the accurate maximum power, the system power losses can not be ignored. Therefore, based on the theory of traditional PF method, an optimum current given the MPPT method and considering torque loss is proposed for the DPF-WECS in this paper. Then the proposed SM-MRAS-based sensorless algorithm is applied to obtain the outer rotor speed and position for realizing the MPPT control strategy.

The structure of the paper is as follows: Section 2 presents the model of the new EVT-based DPF-WECS. Section 3 introduces the sensorless control strategies for the DPF-WECS. Section 4 shows the simulation results of the system while adopting the proposed control method. Section 5 
demonstrates the experimental results and analyzes the effectiveness of the proposed control strategies. Conclusions are given in Section 6.

\section{Model of the DPF-WECS}

\subsection{Power Flow of the DPF-WECS}

The EVT machine is regarded as the combination of two permanent magnet synchronous machines (PMSMs), the outer machine consists of the stator and the outer rotor and the inner machine consists of the inner rotor and the outer rotor. The input power can be separated into electric power $P_{e s}$ (the red line in Figure 1) and mechanical power $P_{d}$ (blue line in Figure 1). The power flow of the DPF-WECS considering the system losses is shown in Figure 2. The mechanical power $P_{d}$ is delivered from the outer rotor to the inner rotor through electromagnetic coupling with high efficiency. The mechanical loss of this power transmission is described as $P_{\text {dloss }}$. The outer machine produces electrical power loss described as $P_{\text {eloss } 1}$, including copper loss and iron loss. The electrical power $P_{e s}$ by deducting the losses is delivered by the stator windings. The loss produced by the converter connected with the stator is described as $P_{\text {closs } 1}$.

Installation of the energy storage system (ESS) can make the output power from the DPF-WECS to the grid adjustable. When the generated power equals the power demand of the grid, no power flows through the ESS. When the EVT machine supplies more power than the grid needs, the redundant power $P_{\text {ess }}$ will be absorbed in the ESS and the loss of the ESS is expressed as $P_{\text {essloss }}$. The power flow in this operation status is shown in Figure 2a. On the contrary, if the power generated by the EVT machine is less than the grid needs, the insufficient power $P_{\text {ess }}$ will be supplied by the ESS and the power flow is shown in Figure $2 b$.

The electrical power $P_{e i}$ is delivered to the inner rotor windings through the inner rotor side inverter from the DC bus. Then the converter loss $P_{\text {closs } 2}$ and the sum of copper loss and iron loss of the inner rotor windings $P_{\text {eloss } 2}$ are generated. Finally, the inner rotor output power $P_{m 2}$ is composed of the mechanical power and the electrical power after deducting the losses.

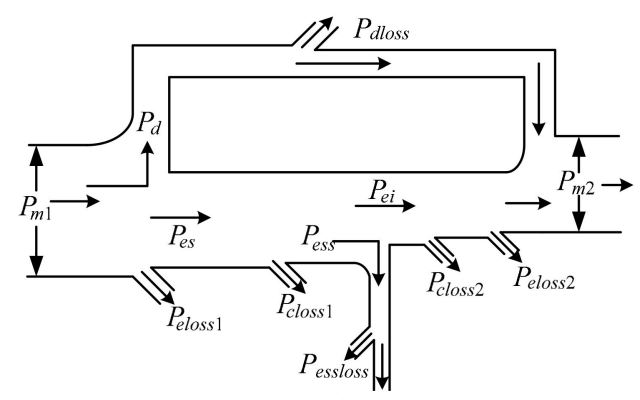

(a) ESS charges.

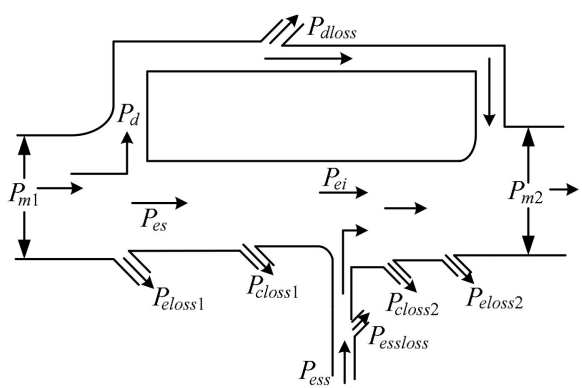

(b) ESS discharges.

Figure 2. Power flow of the DPF-WECS.

\subsection{Mathematical Model of the EVT}

Voltage equations of the EVT machine are given as follows in $d q$-axes rotating frame:

$$
\begin{gathered}
\left\{\begin{array}{c}
u_{d s}=i_{d s} R_{s}+\frac{d \psi_{d s}}{d t}-\omega_{o} \psi_{q s} \\
u_{q s}=i_{q s} R_{s}+\frac{d \psi_{q s}}{d t}+\omega_{o} \psi_{d s}
\end{array}\right. \\
\left\{\begin{array}{l}
u_{d r}=i_{d r} R_{r}+\frac{d \psi_{d r}}{d t}-\left(\omega_{o}-\omega_{i}\right) \psi_{q r} \\
u_{q r}=i_{q r} R_{r}+\frac{d \psi_{q r}}{d t}+\left(\omega_{o}-\omega_{i}\right) \psi_{d r}
\end{array}\right.
\end{gathered}
$$

where $R_{S}$ and $R_{r}$ are the resistance of stator windings and inner rotor windings, respectively. $\omega_{0}$ is the outer rotor speed, and $\omega_{i}$ is the inner rotor speed. $i_{d s}, i_{q s}, i_{d r}, i_{q r}$ are the stator currents and inner 
rotor currents in the $d q$-axes, while $\psi_{d s}, \psi_{q s}, \psi_{d r}, \psi_{q r}$ are the flux linkages, and the equations are given as follows:

$$
\begin{aligned}
& \left\{\begin{array}{l}
\psi_{d s}=\psi_{f o}+L_{s} i_{d s} \\
\psi_{q s}=L_{s} i_{q s}
\end{array}\right. \\
& \left\{\begin{array}{l}
\psi_{d r}=\psi_{f i}+L_{r} i_{d r} \\
\psi_{q r}=L_{r} i_{q r}
\end{array}\right.
\end{aligned}
$$

where $L_{s}$ and $L_{r}$ are the self-inductance of stator windings and inner rotor windings, respectively. $\psi_{f o}$ and $\psi_{f i}$ are the flux-linkage produced by outer and inner layers of magnets, respectively. Other detailed equations of the mathematical model of the EVT machine can be seen in [4].

\subsection{Model of the Wind Turbine}

The mechanical power generated by a WT is:

$$
P_{w}=\rho \pi R^{2} C_{p}(\lambda, \beta) v^{3} / 2
$$

where $\rho$ is the air density, $R$ is the turbine blade radius, $v$ is the wind speed, and $C_{p}$ is the power coefficient, which is a function of the TSR $\lambda$ and the blade pitch angle $\beta . \lambda$ is defined as:

$$
\lambda=\omega_{0} R / v
$$

The output torque of the wind turbine is:

$$
T=\rho \pi R^{3} C_{p}(\lambda, \beta) v^{2} / 2 \lambda
$$

The relationship of the $C_{p}$ and $\lambda$ is shown in Figure 3 by assuming that $\beta$ is zero. According to Equation (6), the generator speed can be adjusted to keep $\lambda$ at the optimum value to maximize the power coefficient as $C_{p \max }$.

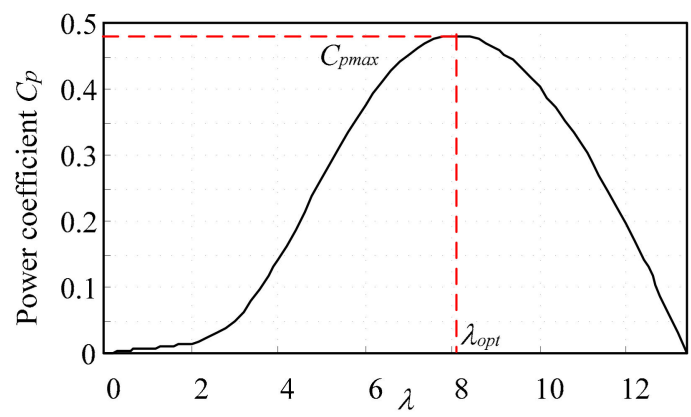

Figure 3. Curve of the tip speed ratio $\lambda$

Representing the rotor speed with the wind speed according to Equation (6) and substituting it into Equation (5), the maximum output power of the WT is:

$$
P_{\text {wopt }}=\rho \pi R^{5} C_{p \max } \omega_{\text {opt }}^{3} / 2 \lambda_{\text {opt }}^{3}=k_{\text {opt }} \omega_{\text {opt }}^{3}
$$

Then dividing the maximum power $P_{\text {wopt }}$ by the optimum generator speed $\omega_{\text {opt }}$, the optimum torque can be obtained as:

$$
T_{o p t}=\rho \pi R^{5} C_{p \max } \omega_{o p t}^{2} / 2 \lambda_{o p t}^{3}=k_{o p t} \omega_{o p t}^{2}
$$

where $k_{o p t}$ is the coefficient associated with the wind turbine characteristics. 


\section{Sensorless Control for the DPF-WECS}

\subsection{SM-MRAS-Based Sensorless Control Strategy}

The mathematical model of the outer machine is considered first for the analysis of the SM-MRAS-based sensorless control. Equation (1) is rewritten as:

$$
\left\{\begin{array}{l}
\frac{d \psi_{d s}}{d t}=-\frac{R_{s} \psi_{d s}}{L_{s}}+\omega_{o} \psi_{q s}+\frac{R_{s} \psi_{f o}}{L_{s}}+u_{d s} \\
\frac{d \psi_{q s}}{d t}=-\frac{R_{s} \psi_{q s}}{L_{s}}-\omega_{0} \psi_{d s}+u_{q s}
\end{array}\right.
$$

Equation (10) is then rewritten into matrix form as follows:

$$
\frac{d}{d t}\left(\begin{array}{l}
\psi_{d s} \\
\psi_{q s}
\end{array}\right)=\left(\begin{array}{cc}
-\frac{R_{s}}{L_{s}} & \omega_{o} \\
-\omega_{e} & -\frac{R_{s}}{L_{s}}
\end{array}\right)\left(\begin{array}{l}
\psi_{d s} \\
\psi_{q s}
\end{array}\right)+\left(\begin{array}{l}
u_{d s}+\frac{R_{s} \psi_{f o}}{L_{s}} \\
u_{q s}
\end{array}\right)
$$

Then the adaptive model of the MRAS observer is derived by replacing the actual value with the estimated value in Equation (11) as:

$$
\frac{d}{d t}\left(\begin{array}{l}
\hat{\psi}_{d s} \\
\hat{\psi}_{q s}
\end{array}\right)=\left(\begin{array}{cc}
-\frac{R_{s}}{L_{s}} & \hat{\omega}_{o} \\
-\hat{\omega}_{e} & -\frac{R_{s}}{L_{s}}
\end{array}\right)\left(\begin{array}{l}
\hat{\psi}_{d s} \\
\hat{\psi}_{q s}
\end{array}\right)+\left(\begin{array}{l}
u_{d s}+\frac{R_{s} \psi_{f o}}{L_{s}} \\
u_{q s}
\end{array}\right)
$$

where` means the estimated value.

Due to the fast dynamic responses of the system and the robustness under the condition of the parametric uncertainties and disturbance, the sliding mode (SM) is a very effective nonlinear control method. A switching control law is defined based on the Lyapunov theory, which can drive the nonlinear state trajectory onto the switching surface, and then keep the trajectory sliding on this surface at all following times. In this paper, the SM strategy is adopted in the MRAS scheme instead of the conventional constant-gain PI regulator for the MPPT control of the outer machine. The manifold $s$ of the SM based on the flux model is built as:

$$
s=\psi_{d s} \hat{\psi}_{q s}-\hat{\psi}_{d s} \psi_{q s}
$$

Then the derivative of the $s$ is described as:

$$
\dot{s}=\dot{\psi}_{d s} \hat{\psi}_{q s}+\psi_{d s} \dot{\hat{\psi}}_{q s}-\dot{\hat{\psi}}_{d s} \psi_{q s}-\hat{\psi}_{d s} \dot{\psi}_{q s}
$$

Substituting Equations (11) and (12) into Equation (14), $\dot{s}$ can be derived as:

$$
\begin{aligned}
& \dot{s}=\omega_{o}\left(\psi_{d s} \hat{\psi}_{d s}+\psi_{q s} \hat{\psi}_{q s}\right)+\frac{2 R_{s}}{L_{s}}\left(\psi_{q s} \hat{\psi}_{d s}-\psi_{d s} \hat{\psi}_{q s}\right)+u_{q s}\left(\psi_{d s}-\hat{\psi}_{d s}\right) \\
& +\left(u_{d s}+\frac{R_{s} \psi_{f o}}{L_{s}}\right)\left(\hat{\psi}_{q s}-\psi_{q s}\right)-\hat{\omega}_{o}\left(\psi_{d s} \hat{\psi}_{d s}+\psi_{q s} \hat{\psi}_{q s}\right)
\end{aligned}
$$

The estimated outer rotor speed of the EVT based on the constant switching SM can be expressed as:

$$
\hat{\omega}_{o}=\operatorname{Msign}(s)
$$

where $M$ is a positive constant, and sign() is the sign function.

By replacing the estimated speed from Equation (16) in Equation (15), it can be obtained that:

$$
\dot{s}=f\left(\omega_{0}, \psi_{d s}, \hat{\psi}_{d s}, \psi_{q s}, \hat{\psi}_{q s}, R_{s}, L_{s}, u_{d s}, u_{q s}\right)-M\left(\psi_{d s} \hat{\psi}_{d s}+\psi_{q s} \hat{\psi}_{q s}\right) \operatorname{sign}(s)
$$

where $f$ is a function of the speed, estimated and reference fluxes and machine parameters. 
Since the term $\psi_{d s} \hat{\psi}_{d s}+\psi_{q s} \hat{\psi}_{q s}$ is positive when the machine is started and $f$ has a positive upper estimate, it can be seen from Equation (17) that there exists a high enough $M$ that can be chosen to fulfill the following expression:

$$
\dot{s i}<0
$$

After that, the SM is enforced in manifold $s=0$.

The method based on the boundary-layer is adopted to seek out the equivalent speed $\omega_{o_{-} e q}$. When the SM happens, it can be assumed that $\dot{s}=0$ along with $s=0$. Then the equivalent speed is derived as:

$$
\omega_{o_{-} e q}=\omega_{0}+\frac{f\left(\omega_{0}, \psi_{d s}, \hat{\psi}_{d s}, \psi_{q s}, \hat{\psi}_{q s}, R_{s}, L_{s}, u_{d s}, u_{q s}\right)}{\psi_{d s} \hat{\psi}_{d s}+\psi_{q s} \hat{\psi}_{q s}}
$$

When the estimated fluxes and the actual fluxes are equal, the second term of Equation (19) tends to zero and the equivalent speed $\omega_{o_{-} e q}$ heads for the real speed. Since the equivalent speed shown in Equation (19) represents the low frequency part of the discontinuous term in Equation (16), the estimated speed can be obtained by separating the low frequency component via using a low pass filter. The structure of the flux model based SM-MRAS is shown in Figure 4.

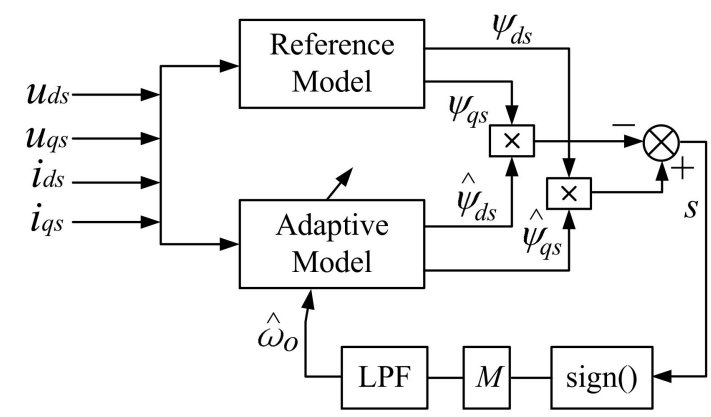

Figure 4. Configuration of the SM-MRAS based on the flux model.

The $i_{d}=0$ control method is frequently applied in the vector control of PMSMs because of its simplicity and effectiveness. Then the manifold $s$ shown in Equation (13) can be simplified when $i_{d}=0$ as:

$$
s=\psi_{f o}\left(\hat{\psi}_{q s}-\psi_{q s}\right)
$$

By merging the constant $\psi_{f o}$ into the positive value $M$, the estimated speed is expressed as:

$$
\hat{\omega}_{o}=\operatorname{Msign}\left(\hat{\psi}_{q s}-\psi_{q s}\right)
$$

For decreasing the undesirable chattering of the SM schemes, the switching function of the estimated speed is improved and described as:

$$
\hat{\omega}_{o}=\left\{\begin{array}{l}
\operatorname{Msign}\left(\hat{\psi}_{q s}-\psi_{q s}\right),\left|\hat{\psi}_{q s}-\psi_{q s}\right|>\varepsilon \\
M\left(\hat{\psi}_{q s}-\psi_{q s}\right) / \varepsilon,\left|\hat{\psi}_{q s}-\psi_{q s}\right| \leq \varepsilon
\end{array}\right.
$$

where $\varepsilon$ is a small positive constant. The estimated position is obtained by integrating the estimated speed.

\subsection{MPPT Control for the DPF-WECS Considering Torque Loss}

As previously stated, the stator and the outer rotor of the EVT can be combined and regarded as a PMSM, called the outer machine. The torque of the outer rotor $T_{m 1}$ includes two parts: the torque $T_{o m}$ produced by the outer magnets and the stator windings, which is also the equivalent torque of the 
outer machine, the torque $T_{i m}$ generated by the inner magnets, and the inner rotor windings, which is also called $T_{m 2}$.

The power of the outer machine in steady state can be obtained based on Equations (1) and (3) as:

$$
P=u_{d s} i_{d s}+u_{q s} i_{q s}=R_{s}\left(i_{d s}^{2}+i_{q s}^{2}\right)+\omega_{o} \psi_{f o} i_{q s}
$$

The first item of Equation (23) is the copper loss; thus, the electromagnetic torque of the outer machine is obtained by getting rid of the copper loss as:

$$
T_{o m}=\left[P-R_{s}\left(i_{d s}^{2}+i_{q s}^{2}\right)\right] / \omega_{o}=n_{p}\left[P-R_{s}\left(i_{d s}^{2}+i_{q s}^{2}\right)\right] / \omega_{o}=n_{p} \psi_{f o} i_{q s}
$$

where $n_{p}$ is the outer machine pole pairs.

To realize the MPPT, the outer rotor torque $T_{m 1}$ should be equal to the maximum torque $T_{\max }$. As stated before, the outer rotor torque equation relationship is:

$$
T_{m 1}=T_{o m}+T_{i m}=T_{o m}+T_{m 2}
$$

Then the optimum torque of the outer machine $T_{\text {om_opt }}$ can be given as:

$$
T_{o m \_o p t}=T_{o p t}-T_{m 2}=k_{o p t} \omega_{o}^{2}-T_{m 2}
$$

The iron loss, copper loss, stray loss, and mechanical loss cannot be ignored, nor can the torque loss when the outer machine is in operation. The copper loss has been considered in the electromagnetic torque equation as shown in Equation (24). Then the torque loss expressed as $T_{\text {loss }}$ only includes the iron loss, stray loss, and mechanical loss.

After adding the iron torque loss, the stray torque loss, and the mechanical torque loss, the total torque loss $T_{\text {loss }}$ is:

$$
T_{\text {loss }}=C_{1}+C_{3}+C_{2} \omega=C+C_{2} \omega
$$

where constant $C$ is combined with $C_{1}$ and $C_{3}$.

Then the actual optimum outer machine torque $T_{\text {om_opt }}$ can be obtained:

$$
T_{\text {om_opt }}=k_{o p t} \omega_{o}^{2}-T_{m 2}-T_{\text {loss }}=k_{o p t} \omega_{o}^{2}-C_{2} \omega_{o}-C-T_{m 2}
$$

The inner rotor speed is a constant which is equal to the synchronous speed of the SG. Then the inner rotor torque $T_{m 2}$ can be calculated based only on the output power of the EVT machine. Considering that $T_{m 2}$ is known, it can be seen from Equation (28) that $T_{\text {om_opt }}$ is only influenced by the optimum outer rotor speed when $C$ and $C_{2}$ is known. The permanent magnet flux $\psi_{f o}$ of the outer machine can be seen as a constant, then $T_{o m}$ is only decided by the stator $q$-axis current $i_{q s}$ as seen in Equation (24). Therefore, the system can achieve the MPPT by obtaining the optimum torque $T_{\text {om_opt }}$ which is directly related to an optimum current $i_{q s_{-} o p t}$. The optimum current $i_{q s_{-} \text {opt }}$ can be expressed as:

$$
i_{q s_{-} o p t}=\frac{k_{o p t} \omega_{o}^{2}-C_{2} \omega_{o}-C-T_{m 2}}{n_{p} \psi_{f o}}
$$

The outer machine torque loss $T_{\text {loss }}$ is crucial to the MPPT's accuracy. The constants $C$ and $C_{2}$ in Equation (29), which are the key factors to calculate the loss torque can be obtained through the algorithm described in detail in [19]. After that, the optimum current can be calculated according to the outer rotor speed $\omega_{0}$ and inner rotor torque $T_{m 2}$. Then the MPPT control of the outer machine, considering the torque loss, is realized by giving the optimum current.

The outer rotor speed and position of the EVT machine is needed to realize the aforementioned MPPT control. The SM-MRAS-based sensorless control strategy is applied here to estimate the outer rotor speed and position for improving the reliability of the MPPT control of the EVT. The control 
block diagram of the outer rotor of the EVT machine is shown in Figure 5. The reference $d$-axis current $i_{d s}^{*}$ is set to zero to simplify the control. The space vector modulation is adopted to generate control pulses for the stator side converter.

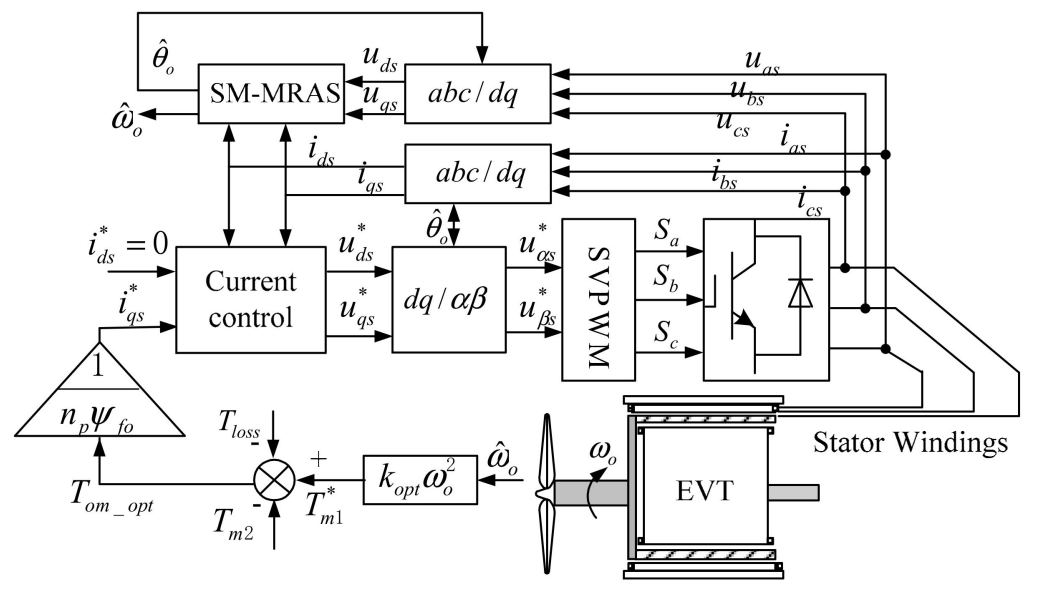

Figure 5. Control configuration of the outer rotor of the EVT.

\subsection{Sensorless Control for the Inner Rotor of the EVT Machine}

The control target of the inner rotor of the EVT is to remain at the steady synchronous speed, thus generating the electricity with constant frequency. The inner rotor speed control comes trued through the inner machine of the EVT. However, the inner machine is different from the traditional machines since both of the two rotors are rotational. The rotor speed of the inner machine is considered as the speed difference between the outer rotor and inner rotor [5]. Then the rotor position of the inner machine is codetermined by the inner rotor and the outer rotor, which can be obtained as:

$$
\theta_{i n}=\int \omega_{i n} d t=\int\left(\omega_{i}-\omega_{0}\right) d t
$$

where $\omega_{\text {in }}$ is the speed of the inner machine. Based on Equation (30), both the outer rotor speed and inner rotor speed are required to calculate the position $\theta_{i n}$. Afterwards, the errors may be produced by the sensors in the process of detecting the rotor speed and position. Additinoally, the error of the position will be larger due to the accumulation of the detected values through sensors. Thus, the above-mentioned sensorless control based on the SM-MRAS is applied to the inner machine, as well as the outer machine, to increase the detecting accuracy of the inner rotor speed and position.

The control strategies of the inner rotor, when the system is off grid and on grid, are both given in Figure 6. The inner rotor speed has to be regulated to rotate at the synchronous speed to reach the grid frequency when the system is off grid. However, the control strategy for the inner rotor side converter will be changed when the WECS is on grid due to the inner rotor speed being determined by the grid frequency at this moment. Thus, the inner rotor side inverter is used to regulate the DC link to ensure the voltage remains constant. The given reference DC link voltage is compared with the real value and the difference is given to a PI regulator. Then the output is the reference inner rotor $q$-axis current. The same as the outer rotor control, the reference $d$-axis current of the inner rotor windings $i^{*}{ }_{d r}$ is set to 0 and space vector modulation is adopted to generate control pulses for the inner rotor side converter. 


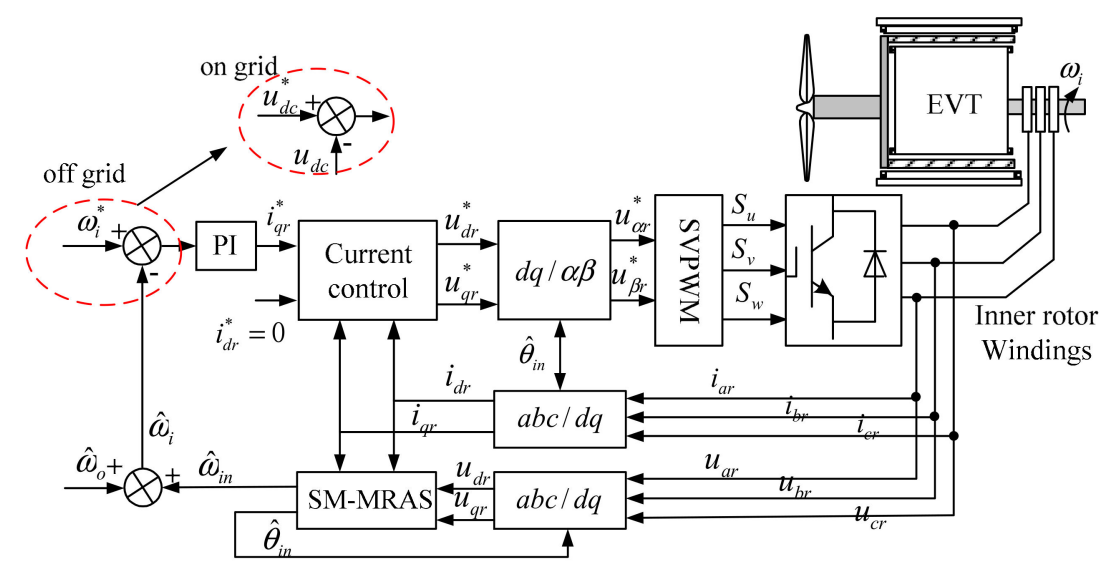

Figure 6. Control configuration of the inner rotor of the EVT.

\section{Simulation Validation}

The model of the DPF-WECS is built in MATLAB/Simulink (MathWorks, Natick, MA, USA) to verify the proposed sensorless control strategies. In the simulation, the wind turbine parameters are shown in Table 1. The rated power of the EVT machine is $10 \mathrm{~kW}$ and the parameters are given in Table 2. The rated speed of the outer rotor is $300 \mathrm{rpm}$ and the rated speed of the inner rotor is $1000 \mathrm{rpm}$. The simulation parameters are based on the designed prototype EVT machine, in agreement with the experimental parameters.

Table 1. Parameters of the wind turbine.

\begin{tabular}{cc}
\hline Items & Wind Turbine \\
\hline Rotor Radius $(\mathrm{m})$ & 2.84 \\
Air density $\left(\mathrm{kg} / \mathrm{m}^{3}\right)$ & 1.225 \\
Optimum tip speed ratio & 8.1 \\
Optimum wind power coefficient & 0.48 \\
Rated wind speed $(\mathrm{m} / \mathrm{s})$ & 11 \\
Rated power $(\mathrm{kW})$ & 10 \\
\hline
\end{tabular}

Table 2. Parameters of the EVT machine.

\begin{tabular}{ccc}
\hline Items & Outer Machine & Inner Machine \\
\hline Resistance $(\Omega)$ & 0.54 & 0.14 \\
$d$-axis inductance $(\mathrm{mH})$ & 13 & 3.5 \\
$q$-axis inductance $(\mathrm{mH})$ & 13 & 3.5 \\
Inertia $\left(\mathrm{kg} \cdot \mathrm{m}^{2}\right)$ & 0.55 & 0.16 \\
Permanent Magnet flux-linkage $(\mathrm{Wb})$ & 1.86 & 0.49 \\
Pole pairs & 6 & 6 \\
\hline
\end{tabular}

In the simulation, the proposed MPPT method is applied for the outer rotor of the EVT. Additionally, the SM-MRAS-based sensorless strategy is applied in both the outer rotor and inner rotor control. The direct current (DC) link of the DPF-WECS is equipped without the ESS in order to be consistent with the experimental conditions. The DPF-WECS is on grid in the simulation. The simulation results are shown in Figure 7a-h.

Figure 7a shows the outer rotor speed of the EVT which matches well with the optimum speed under the condition that the wind speed is below the rated value (300 rpm). The outer rotor speed maintains the rated speed when the wind speed is over the rated value. Thus, the effectiveness of the MPPT control is verified. Figure $7 \mathrm{~b}$ demonstrates the phase A current of the stator whose amplitude 
varies with the outer rotor speed while the expanded figure shows the good sinusoidal character. Figure $7 \mathrm{c}$ shows the outer rotor torque and stator torque of the EVT and the difference of the two torques is equal to the inner rotor torque. The DC link voltage is given in Figure $7 \mathrm{~d}$ and it can be seen that it remains at the reference value of $580 \mathrm{~V}$ only with tiny fluctuation.

The speed, current, and torque of the inner rotor are presented in Figure $7 \mathrm{e}-\mathrm{g}$ respectively. The inner rotor speed remains constant when the DPF-WECS is on grid. It can be observed from the expanded drawing that the inner rotor current is quite sinusoidal. The amplitude of phase A current and inner rotor torque also vary with the wind speed because the power absorbed from the outer rotor are all transmitted to the SG from the inner rotor by deducting the losses. The input and output power are demonstrated in Figure $7 \mathrm{~h}$.

The above simulation results verify the validity of the proposed control strategies, including the SM-MRAS-based sensorless MPPT control for the outer rotor and on-grid inner rotor control strategies for the DPF-WECS.

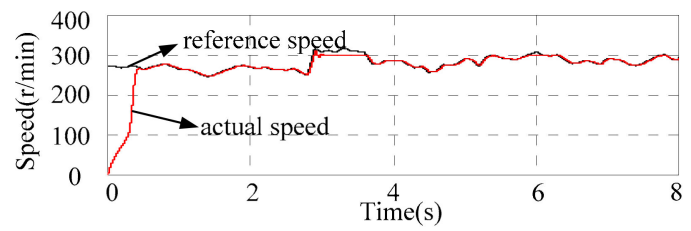

(a) Outer rotor speed.

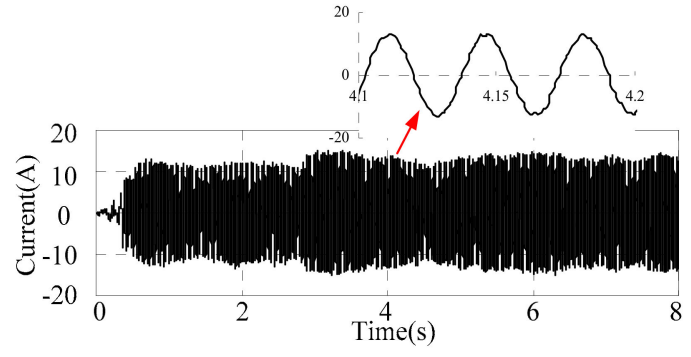

(b) Phase A current of the stator.

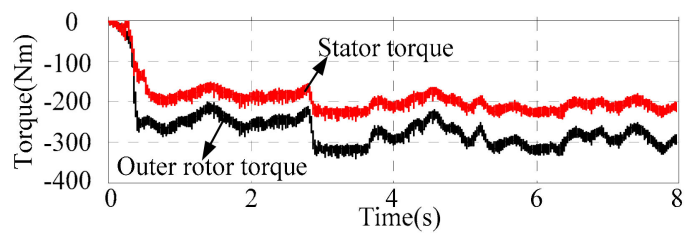

(c) Stator torque and outer rotor torque.

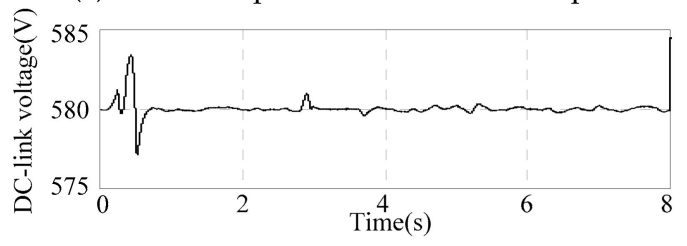

(d) DC-link voltage.

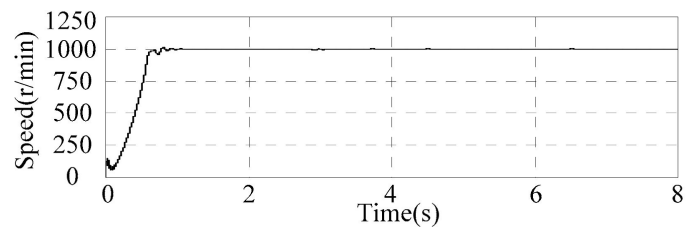

(e) Inner rotor speed.

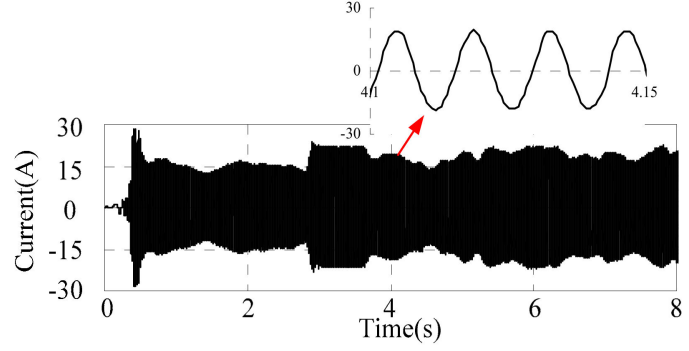

(f) Phase A current of the inner rotor.

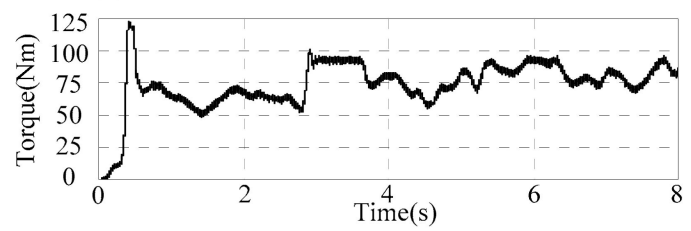

(g) Inner rotor torque.

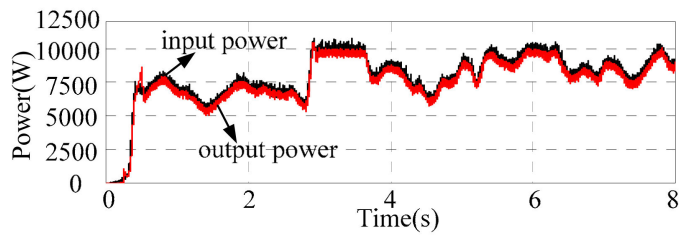

(h) Input power and output power of the DPF-WECS.

Figure 7. Simulation results of the DPF-WECS.

\section{Experimental Validation}

\subsection{Experimental Platform of the DPF-WECS}

The experimental platform of the DPF-WECS is shown in Figure 8. It mainly consists of a $10 \mathrm{~kW}$ permanent magnet EVT machine, a reduction gearbox, an $11 \mathrm{~kW}$ induction motor, and a $5.5 \mathrm{~kW}$ PMSG. The WT is imitated by the induction motor (IM) and the reduction gearbox with a ratio of 4.2. 
The parameters of the IM for the imitation of the wind turbine is shown in Table 3. The control of the IM and the EVT machine is based on the dSPACE DS1103 (dSPACE, Paderborn, Germany).

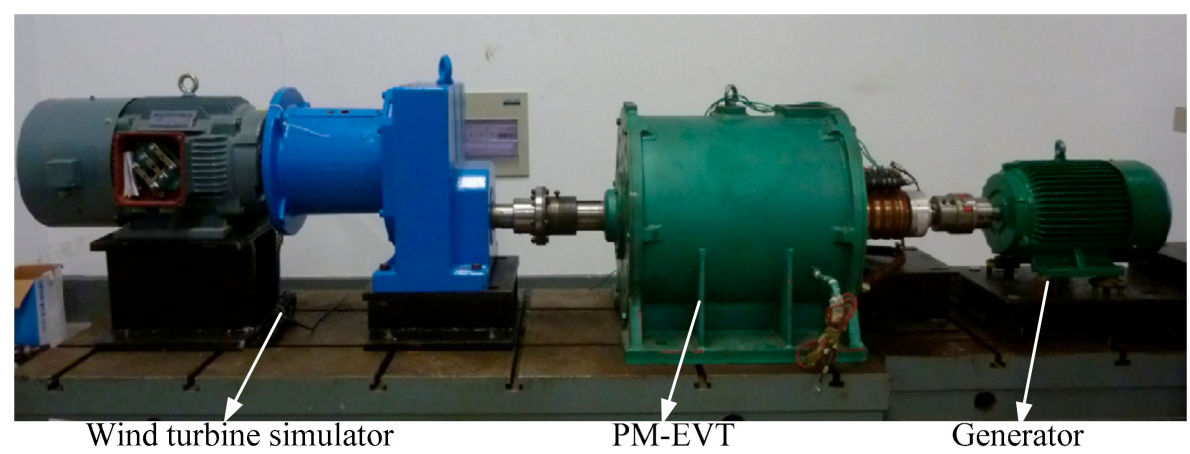

Figure 8. Experimental platform of the DPF-WECS.

Table 3. Parameters of the IM for the imitation of the wind turbine.

\begin{tabular}{cc}
\hline Items & Induction Motor \\
\hline Stator resistance $(\Omega)$ & 0.385 \\
Rotor resistance $(\Omega)$ & 0.393 \\
Stator leakage inductance $(\mathrm{mH})$ & 1.9 \\
Rotor leakage inductance $(\mathrm{mH})$ & 1.9 \\
Mutual inductance $(\mathrm{mH})$ & 85.7 \\
Rated speed $(\mathrm{r} / \mathrm{min})$ & 1450 \\
\hline
\end{tabular}

\subsection{Validation of the SM-MRAS Sensorless MPPT Control}

For testing the performance of the proposed SM-MRAS sensorless MPPT control, the experimental control platform is shown in Figure 9, where the inner rotor of the EVT is out of control at this time.

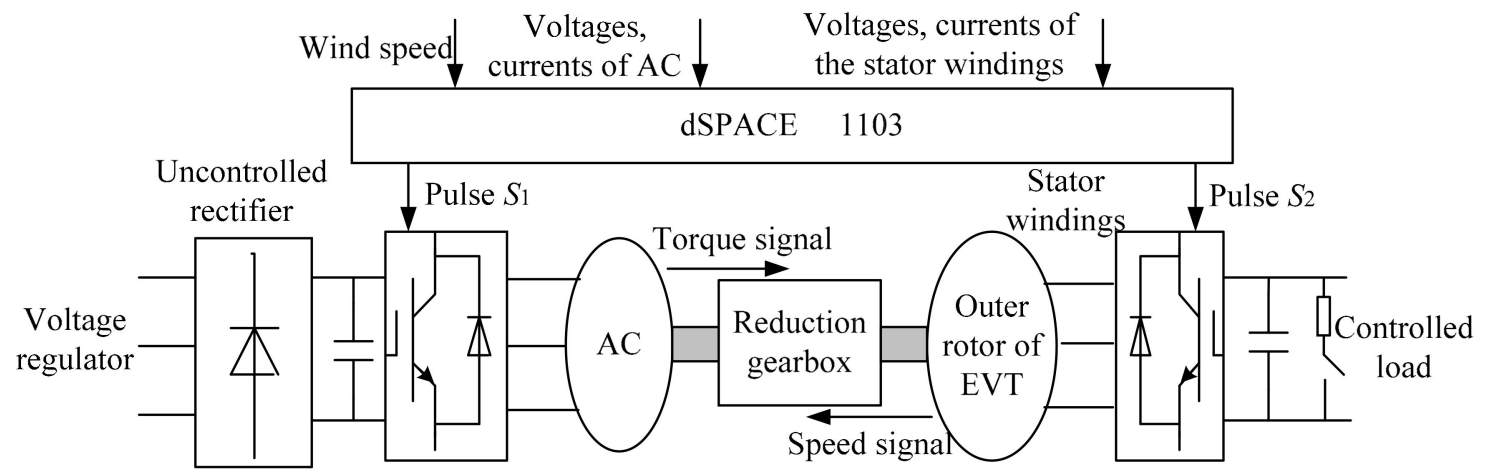

Figure 9. Experimental control platform for testing the sensorless MPPT strategy.

The direct torque control (DTC) strategy is employed for the IM control to improve the torque response speed and then achieve the good performance of the WT imitation. The experimental results of the WT imitation are demonstrated in Figure 10. Firstly, the DTC method for the induction motor is the adopted speed regulation control with no load. The reference speed of the induction motor is given from $550 \mathrm{rpm}$ to $600 \mathrm{rpm}$ and then to $550 \mathrm{rpm}$. It can be seen from Figure 10a that the DTC control for realizing the speed regulation is achieved successfully and the torque is relatively stable when the speed is changed. Then torque control is applied for the induction motor to imitate the WT. The given wind speed is $4 \mathrm{~m} / \mathrm{s}, 5 \mathrm{~m} / \mathrm{s}$, and $6 \mathrm{~m} / \mathrm{s}$ while the outer rotor speed of the EVT is given from $20 \mathrm{rpm}$ to $200 \mathrm{rpm}$ with recording a time every $10 \mathrm{rpm}$. The output torque of the induction motor is given in 
Figure 10b. It can be found that the experimental torque results are coincident with the ideal wind turbine curves; thus, the imitation of the wind turbine is realized.

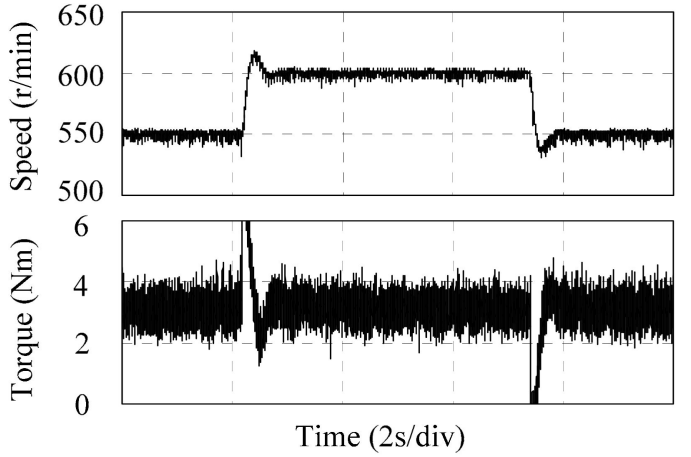

(a) Speed and torque of the induction motor with no load.

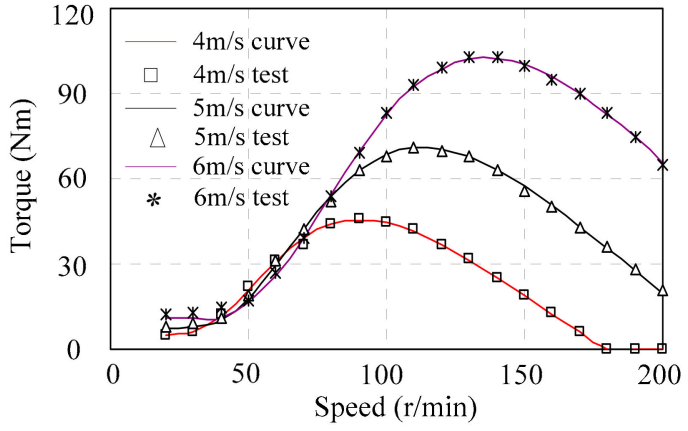

(b) Imitated wind turbine characteristics.

Figure 10. Experimental results of the imitated wind turbine.

The experimental results of the outer rotor of the EVT machine with the sensorless control are shown in Figures 11-13. For testing the low-speed performance of the sensorless control, the reference speed of the outer rotor is from $50 \mathrm{rpm}$ up to $80 \mathrm{rpm}$ and down to $50 \mathrm{rpm}$ by limiting the changing rate with no load. The experimental results under the traditional PI-based MRAS control and proposed SM-MRAS control are shown in Figures 11 and 12, respectively. It can be seen from the results that the sensorless control can be realized both when under the traditional MRAS control and the proposed SM-MRAS. The proposed SM-based MRAS sensorless control performs similarly with the traditional PI-based MRAS sensorless control when the outer rotor speed is $50 \mathrm{r} / \mathrm{min}$. However, the performance of the SM-MRAS sensorless control is better than the PI-based MRAS sensorless control when the outer rotor speed is changed to $80 \mathrm{r} / \mathrm{min}$, which indicates that the PI parameters should be adjusted slightly to ensure good performance while adopting the traditional PI-based MRAS control. Thus, the SM-MRAS-based sensorless control performs better than the traditional PI-based MRAS sensorless control.

The experimental results of the outer rotor with load are shown in Figure 13, while the reference speed and load change during the control process. The outer rotor speed sensorless control has strong performance when both the load suddenly changes and the reference speed changes, as shown in Figure 13a. The phase A current of the stator windings presented in Figure 13b is almost sinusoidal.

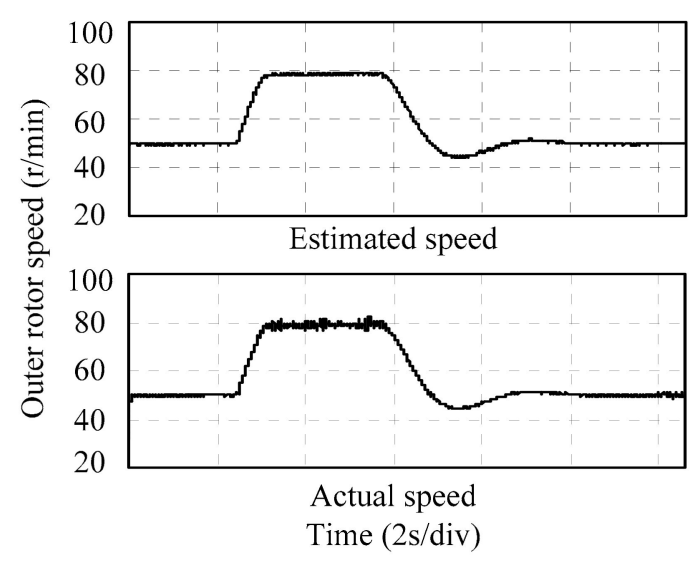

(a) Estimated and actual outer rotor speed.

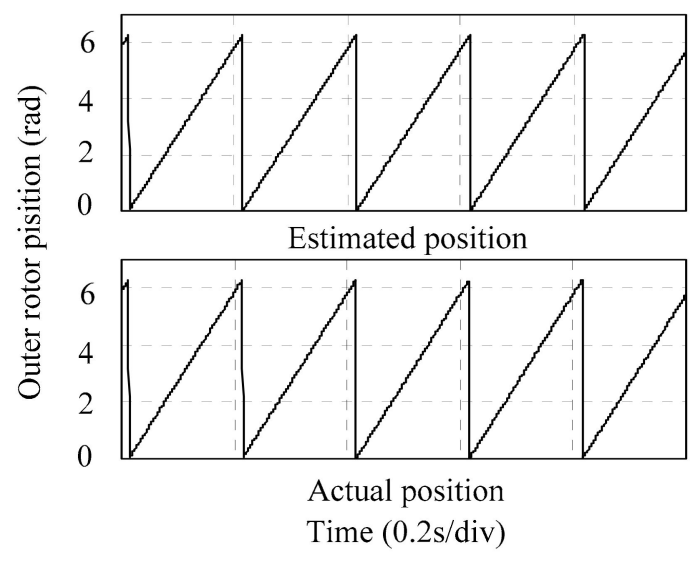

(b) Estimated and actual outer rotor position.

Figure 11. Experimental results of the outer rotor under the PI-based traditional MRAS control. 
After the validation of the sensorless MPPT control method by giving the step reference speed, the stochastic wind speed is given for further validation. For achieving the proposed MPPT control, the torque loss should be estimated, as shown in Equation (29). Then the constants $C$ and $C_{2}$ in Equation (27), which are the key factors, must be obtained first. The detailed method for estimating the torque loss can be seen in [19]. In the experiment, the relationship of the torque loss and the outer rotor speed is tested as $T_{\text {loss }}=15.5+0.3 \omega_{0}$ by using the estimation method in [19]. Then experimental results of the outer rotor are presented in Figure 14 by adopting the proposed optimum current given MPPT control method. It can be seen that the outer rotor speed and the outer rotor torque can follow the reference values well, which indicate that the MPPT is achieved successfully. The output power of the stator presented in Figure 14b is maximized when the wind speed varies.

In conclusion, the experimental results validate the good performance of the SM-MRAS-based sensorless MPPT control strategy for the DPF-WECS.

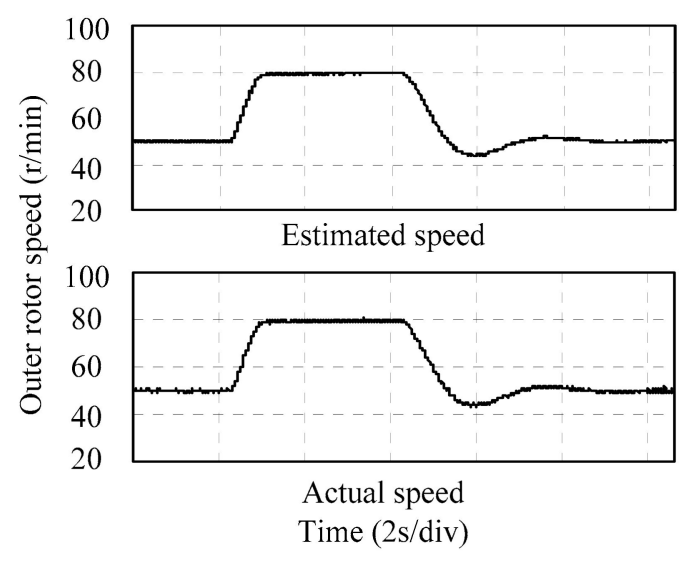

(a) Estimated and actual outer rotor speed.

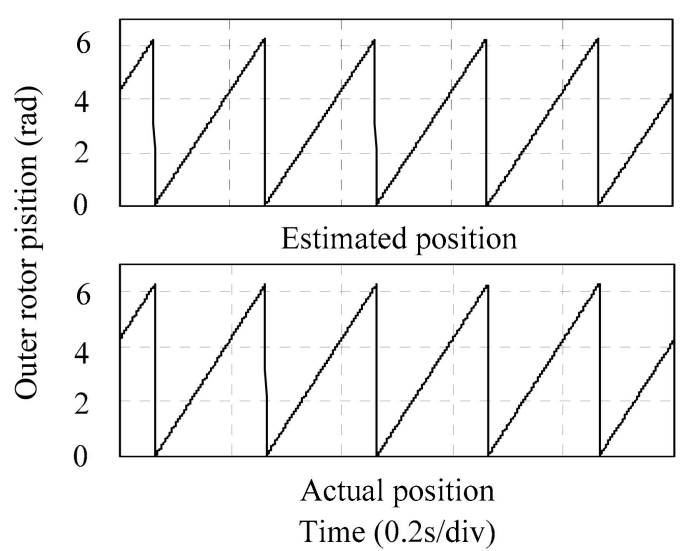

(b) Estimated and actual outer rotor position.

Figure 12. Experimental results of the outer rotor under the SM-MRAS sensorless control.

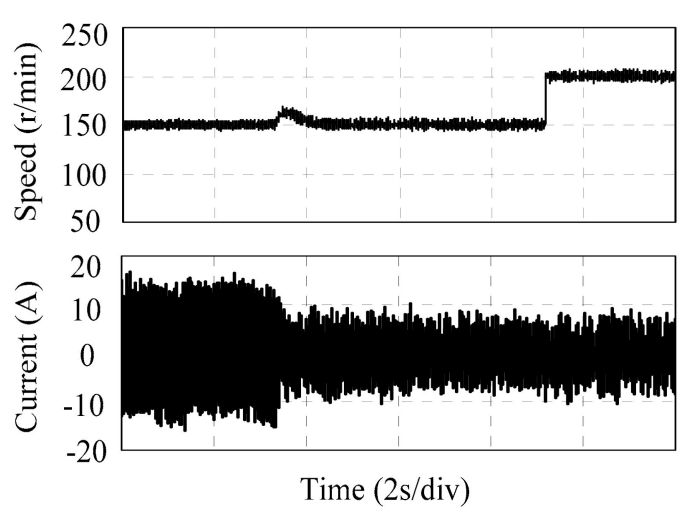

(a) Outer rotor speed and phase A stator current.

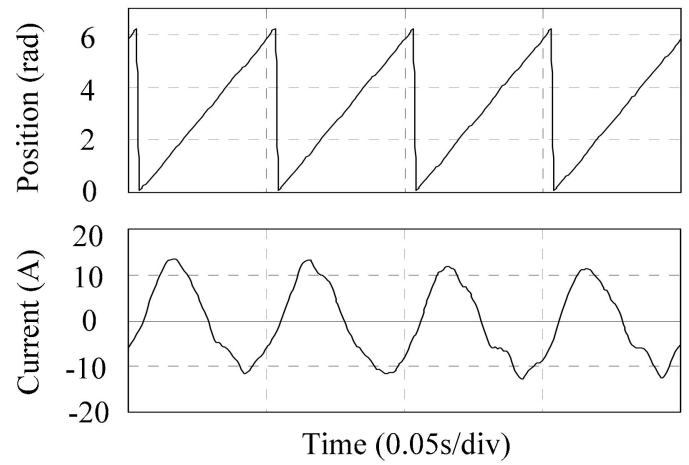

(b) Outer rotor position and phase A stator current.

Figure 13. Experimental results of the outer rotor of the EVT machine with load. 


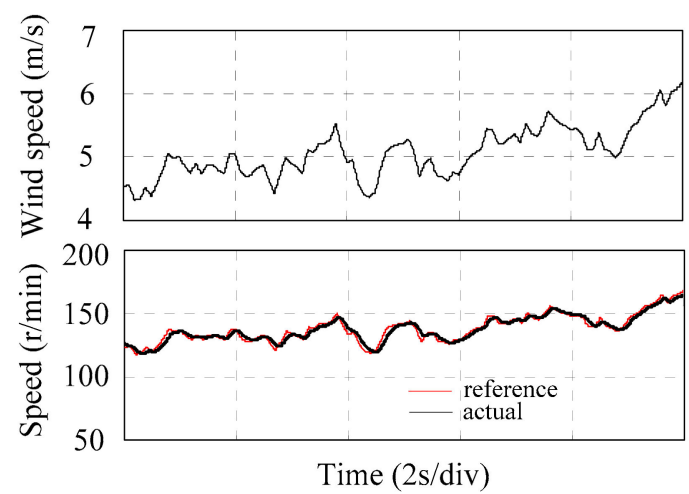

(a) Wind speed and outer rotor speed.

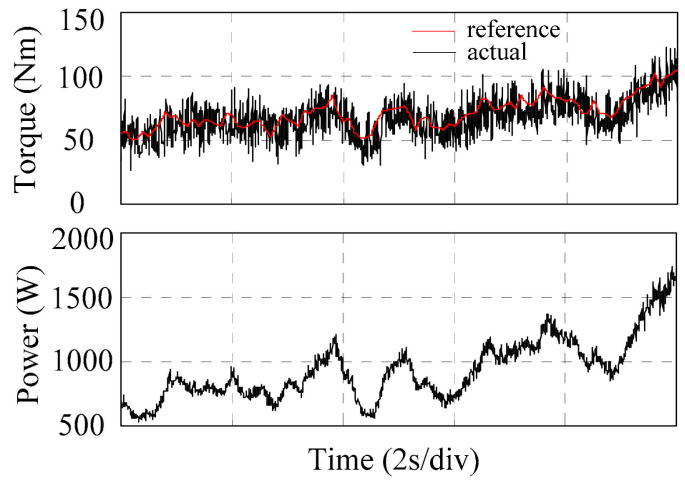

(b) Outer rotor torque and output power.

Figure 14. Experimental results of the MPPT control for the DPF-WECS.

\subsection{Validation of the Sensorless Control for the Inner Rotor}

The performance of the proposed SM-MRAS sensorless control for the inner rotor of the EVT machine is tested where, at this time, the SM-MRAS sensorless MPPT control is applied for the outer rotor. The inner rotor speed of the EVT machine is controlled to maintain a constant speed while the outer rotor speed is given the reference step speed. The experimental results of the inner rotor are presented in Figure 15. It can be known from Figure 15a that the inner rotor speed remains at $300 \mathrm{r} / \mathrm{min}$ while the outer rotor speed is changing. At this point, the sensorless control for the outer rotor is successful and the estimated and the actual outer rotor speed match well, as shown in the extended waveform. The inner rotor position and phase A current are presented in Figure 15b, showing that the estimated position is coincident with the actual position and the phase A current of the inner rotor windings are relatively sinusoidal. Thus, the proposed SM-MRAS-based sensorless control for the whole system is achieved, which is both applied to the outer rotor and inner rotor.

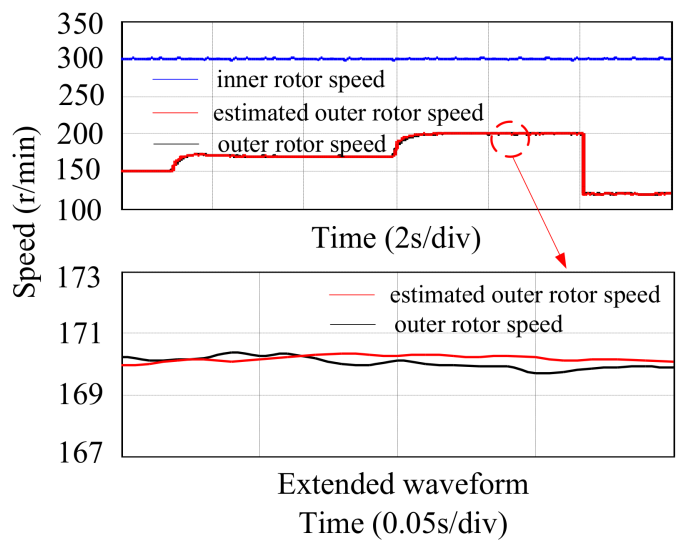

(a) Inner rotor and outer rotor speed.
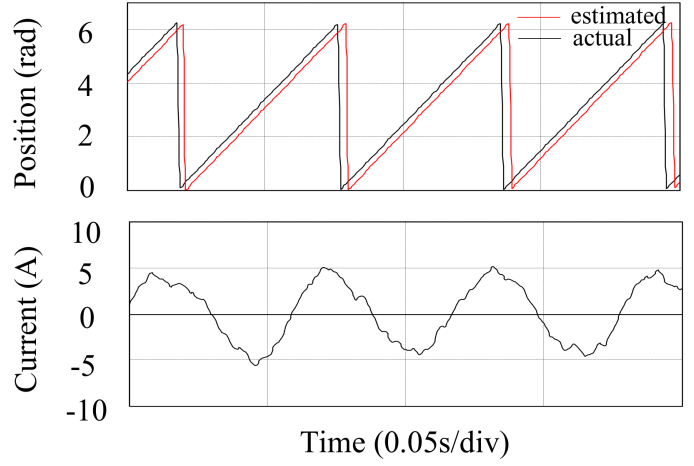

(b) Position and phase A current of the inner rotor.

Figure 15. Experimental results of the sensorless control for DPF-WECS.

\section{Conclusions}

In this paper, a SM-MRAS-based sensorless control strategy is proposed for the DPF-WECS which is applied to the two rotors of the EVT machine to enhance the system robustness. First, the sensorless-based MPPT control method, which is realized by the optimum $q$-axis current calculation of the stator, is adopted for the outer rotor. Additionally, the torque loss of the outer rotor is considered to improve the MPPT efficiency. Furthermore, the proposed sensorless control strategy is adopted to 
control the inner rotor to improve the control precision. Finally, the effectiveness and performance of the proposed sensorless control strategies are validated by the simulation and experimental results.

The proposed sensorless control strategy is meaningful for the EVT machines, which are applied in other fields. Furthermore, the research work in this paper can provide thought for the control of machines with double rotors, though the proposed SM-MRAS-based sensorless control strategy itself is not so novel.

Acknowledgments: This work is supported by grants from the National Natural Science foundation of China (project no. 51507050), the Natural Science foundation of Jiangsu Province (project no. BK20150822) and the Fundamental Research Funds for the Central Universities (project no. 2014B12714).

Author Contributions: Ying Zhu was in charge of the work listed as: searching the literature; proposing the sensorless control strategy for the EVT-based new dual power flow wind energy conversion system; building the simulation model of the DPF-WECS, and verifying the control strategy through the simulation; building the experimental platform and verifying the control strategy through the experiments; and making charts and writing the article. Ming Cheng was the presenter of the new dual power flow wind energy conversion system. Haixiang Zang was in charge of analyzing the data and making some charts of this paper.

Conflicts of Interest: The authors declare no conflict of interest.

\section{References}

1. Cheng, M.; Zhu, Y. The state of the art of wind energy conversion systems and technologies: A review. Energy Convers. Manag. 2014, 88, 332-347. [CrossRef]

2. Liserre, M.; Cardenas, R.; Molinas, M.; Rodriguez, J. Overview of multi-MW wind turbines and wind parks. IEEE Trans. Ind. Electron. 2011, 58, 1081-1095. [CrossRef]

3. Polinder, H.; Van der Piji, F.F.A.; De Vilder, G.J.; Tavner, P.J. Comparison of direct-drive and geared generator concepts for wind turbines. IEEE Trans. Energy Convers. 2006, 21, 725-733. [CrossRef]

4. Sun, X.; Cheng, M.; Zhu, Y.; Xu, L. Application of electrical variable transmission in wind power generation system. IEEE Trans. Ind. Appl. 2013, 49, 1299-1307. [CrossRef]

5. Zhu, Y.; Cheng, M.; Hua, W.; Zhang, B. Sensorless control strategy of electrical variable transmission machines for wind energy conversion systems. IEEE Trans. Magn. 2013, 49, 3383-3386. [CrossRef]

6. Finch, J.W.; Giaouris, D. Controlled AC electrical drives. IEEE Trans. Ind. Electron. 2008, 55, 1-11. [CrossRef]

7. Shi, Y.; Sun, K.; Huang, L.; Li, Y. Online identification of permanent magnet flux based on extended kalman filter for IPMSM drive with position sensorless control. IEEE Trans. Ind. Electron. 2012, 59, 4169-4178. [CrossRef]

8. Wu, X.; Wang, H.; Huang, S.; Huang, K.; Wang, L. Sensorless Speed Control with Initial Rotor Position Estimation for Surface Mounted Permanent Magnet Synchronous Motor Drive in Electric Vehicles. Energies 2015, 8, 11030-11046. [CrossRef]

9. Li, S.; Haskew, T.A.; Swatloski, R.P.; Gathings, W. Optimal and direct-current vector control of direct-driven wind turbines. IEEE Trans. Power Electron. 2012, 27, 2325-2337. [CrossRef]

10. Qiao, W.; Yang, X.; Gong, X. Wind speed and rotor position sensorless control for direct-drive PMG wind turbines. IEEE Trans. Ind. Appl. 2012, 48, 3-11. [CrossRef]

11. Gadoue, S.M.; Giaouris, D.; Finch, J.W. MRAS Sensorless Vector Control of an Induction Motor Using New Sliding-Mode and Fuzzy-Logic Adaptation Mechanisms. IEEE Trans. Energy Convers. 2010, 25, 394-402. [CrossRef]

12. Comanescu, M.; Xu, L. Sliding-mode MRAS speed estimators for sensorless vector control of induction machine. IEEE Trans. Ind. Electron. 2006, 53, 146-153. [CrossRef]

13. Luo, X.; Niu, S. Maximum Power Point Tracking Sensorless Control of an Axial-Flux Permanent Magnet Vernier Wind Power Generator. Energies 2016, 9, 581. [CrossRef]

14. Zhang, X.; Huang, C.; Hao, S.; Chen, F.; Zhai, J. An Improved Adaptive-Torque-Gain MPPT Control for Direct-Driven PMSG Wind Turbines Considering Wind Farm Turbulences. Energies 2016, 9, 977. [CrossRef]

15. Agarwal, V.; Aggarwal, R.K.; Patidar, P.; Patki, C. A novel scheme for rapid tracking of maximum power point in wind energy generation systems. IEEE Trans. Energy Convers. 2010, 25, 228-236. [CrossRef]

16. Pan, C.; Juan, Y. A novel sensorless MPPT controller for a high-efficiency microscale wind power generation system. IEEE Trans. Energy Convers. 2010, 25, 207-216. 
17. Raza Kazmi, S.M.; Goto, H.; Gao, H.; Ichinokura, O. A novel algorithm for fast and efficient speed-sensorless maximum power point tracking in wind energy conversion systems. IEEE Trans. Ind. Electron. 2011, 58, 29-36. [CrossRef]

18. Huang, C.; Li, F.; Jin, Z. Maximum power point tracking strategy for large-scale wind generation systems considering wind turbine dynamics. IEEE Trans. Ind. Electron. 2015, 62, 2530-2539. [CrossRef]

19. Zhu, Y.; Cheng, M.; Hua, W.; Wang, W. A Novel Maximum Power Point Tracking Control for Permanent Magnet Direct Drive Wind Energy Conversion Systems. Energies 2012, 5, 1398-1412. [CrossRef]

(C) 2017 by the authors. Licensee MDPI, Basel, Switzerland. This article is an open access article distributed under the terms and conditions of the Creative Commons Attribution (CC BY) license (http:/ / creativecommons.org/licenses/by/4.0/). 